Jurnal Penelitian Pendidikan, Psikologi Dan Kesehatan (J-P3K) 2021, Vol. 2 (No. 1) : 7-13

\title{
Asesmen Psikologis Korban Bencana Banjir Bandang Aceh Tengah
}

\section{Psychological Assessment of Disaster Victims Flash floods in Central Aceh}

\author{
Ika Amalia(1)*, Ella Suzanna(2) \& Rahmia Dewi(3) \\ Program Studi Psikologi, Fakultas Kedokteran, Universitas Malikussaleh, Indonesia
}

Disubmit: 24 November 2020; Diproses: 25 November 2020; Diaccept: 14 Februari 2021; Dipublish: 05 April 2021 *Corresponding author: ika.amalia@unimal.ac.id

\begin{abstract}
ABSTRAK
Banjir bandang merupakan banjir yang bersifat cepat dan umumnya membawa material tanah berupa lumpur, batu, dan kayu. Akibat dari kecepatan aliran banjir yang disertai dengan material tersebut, maka banjir bandang ini sifatnya sangat merusak dan menimbulkan korban jiwa. Bencana banjir bandang yang terjadi di Kampung Paya Tumpi Baru, dan beberapa kampung lainnya di Kabupaten Aceh Tengah, Propinsi Aceh, merupakan bencana banjir bandang yang cukup besar dan memberikan dampak yang signifikan terhadap masyarakat. Bencana tidak hanya menimbulkan ketakutan tetapi juga mengakibatkan depresi. Kurangnya informasi mengenai dampak psikologis yang ditimbulkan dari bencana banjir bandang pada masyarakat di Aceh Tengah dan belum adanya program yang memetakan kebutuhan psikososial pada korban bencana banjir bandang Aceh Tengah menjadi alasan untuk melakukan program pengabdian kepada masyarakat ini. Tujuan kegiatan ini adalah Untuk mendapatkan informasi mengenai dampak psikologis yang ditimbulkan dari bencana banjir bandang pada masyarakat Aceh Tengah, dan untuk memetakan kebutuhan psikososial pada korban bencana banjir bandang Aceh Tengah. Metode yang digunakan dalam kegiatan ini yaitu menggunakan wawancara dan observasi kepada korban yang terkena dampak bencana banjir di Kabupaten Aceh Tengah.
\end{abstract}

Kata Kunci: Bencana; Banjir Bandang; Aceh Tengah

\begin{abstract}
Flash floods are floods that are fast in nature and generally carry soil material in the form of mud, stones and wood. As a result of the speed of the flood flow accompanied by these materials, this flash flood is very destructive and causes casualties. The flash flood disaster that occurred in Paya Tumpi Baru Village, and several other villages in Central Aceh District, Aceh Province, was a flash flood disaster that was quite large and had a significant impact on the community. Disasters not only cause fear but also cause depression. Lack of information about the psychological impact of banjir bandang disasters on communities in Central Aceh and the absence of a program that maps the psychosocial needs of victims of the flash flood disaster in Central Aceh are reasons to carry out this community service program. The purpose of this activity is to obtain information about the psychological impact of the flash flood disaster on the people of Central Aceh, and to map the psychosocial needs of victims of the flash flood disaster in Central Aceh. The method used in this activity is to use interviews and observations to victims affected by the flood disaster in Central Aceh District.
\end{abstract}

Keywords: Disaster; Flash floods; Central Aceh

DOI: https://doi.org/10.51849/j-p3k.v2i1.69

Rekomendasi mensitasi :

Amalia, I., Suzanna, E., \& Dewi, R. (2021), Asesmen Psikologis Korban Bencana Banjir Bandang Aceh Tengah. Jurnal Penelitian Pendidikan, Psikologi dan Kesehatan (JP3K), 2 (1): 7-13. 


\section{PENDAHULUAN}

Akhir-akhir ini di Indonesia menunjukkan semakin meningkatnya gejala bencana seperti angin puting beliung, badai, banjir, hujan ekstrim, dan lain-lain. Secara umum banjir adalah suatu kejadian dimana air di dalam saluran meningkat dan melampaui kapasitas daya tampungnya.

Terdapat bermacam banjir yaitu banjir hujan ekstrim, banjir kiriman, banjir hulu, banjir rob, dan banjir bandang. Setiap jenis banjir tersebut memiliki karakteristik yang khas.

Banjir bandang adalah kejadian banjir yang singkat dalam waktu sekitar 6 jam yang disebabkan oleh hujan lebat, bendungan jebol, dan tanggul jebol. Banjir bandang ini dikarakterisasikan dengan cepatnya kenaikan muka air sungai/saluran.

Dalam proses kejadian banjir bandang, longsor adalah yang pertama terjadi yang dipicu oleh terjadinya hujan, selanjutnya banjir bandang merupakan kejadian berikutnya sebagai kelanjutan dari kejadian longsor (Larsen, Conde, \& Clark, 2001).

Banjir bandang merupakan banjir yang sifatnya cepat dan pada umumnya membawa material tanah (berupa lumpur), batu, dan kayu. Akibat dari kecepatan aliran banjir yang disertai dengan material tersebut, maka biasanya banjir bandang ini sifatnya sangat merusak dan menimbulkan korban jiwa pada daerah yang dilalui disebabkan tidak sempatnya dilakukan evakuasi pada saat kejadian, dan kerusakan pada bangunan terjadi karena gempuran banjir yang membawa material.
Bencana banjir bandang yang terjadi pada tanggal 13 Mei 2020 di Kampung Paya Tumpi Baru, dan beberapa kampung lainnya di Kabu paten Aceh Tengah, Propinsi Aceh, merupakan bencana banjir yang cukup besar dan memberikan dampak terhadap masyarakat.

Berdasarkan laporan yang diteri ma wartawan dari Koordinator Taruna Siaga Bencana (Tagana) Aceh Tengah, sebanyak 47 kepala keluarga terdampak banjir bandang, dan 57 jiwa mengungsi akibat banjir bandang yang terjadi di daerah dataran tinggi itu. Di Kecamatan Kebayakan bencana terjadi di kampung Paya Tumpi Induk yang berimbas kepada $11 \mathrm{KK}$ dengan 33 jiwa, Kampung Paya Tumpi Baru 7 KK atau 24 Jiwa, dan Kampung Pinangan 29 KK atau 96 jiwa. Kecamatan Bebesen di Kampung Daling dengan korban terdampak $19 \mathrm{KK}$ dan 48 jiwa (Bahagia, 2020).

Musibah banjir bandang terjadi sekitar pukul 14.30 WIB, seiring dengan hujan deras yang mengguyur daerah itu. Bencana banjir ini juga menyebabkan dua warga mengalami luka ringan, yakni 1 warga Kampung Paya Tumpi Baru dan seorang korban lagi merupakan warga Kampung Paya Tumpi Induk.

Sementara jumlah pengungsi dari Kampung Paya Tumpi Induk mencapai $11 \mathrm{KK}$ atau 33 Jiwa. Lalu di Kampung Paya Tumpi Baru berjumlah $7 \mathrm{KK}$ atau 24 Jiwa. Total pengungsi mencapai 57 jiwa. Kerusakan yang terjadi akibat bencana ini sangat bervariasi karena terdapat rumah warga yang mengalami rusak berat, sedang maupun ringan. 
Ketinggian air yang masuk ke perkarangan rumah warga pun menca pai 50 sentimeter hingga 1,5 meter.

Bencana yang terjadi di tengah hujan deras itu menyebabkan satu unit mobil milik Kepala Desa Paya Tumpi terseret air dan material lumpur yang bercampur batu dan kayu. Tidak hanya itu, terdapat satu unit mobil lainnya yang hanyut terbawa banjir sejauh lebih kurang 30 meter. Banjir menimbulkan kerugian secara material dan non material. Selain mengganggu aktivitas masyarakat juga menimbulkan masalah kesehatan.

Banjir bandang ini harus menjadi perhatian serius bagi pemerintah karena dampak yang ditimbulkannya sangat merugikan para korban, seperti; kesulitan air bersih, menimbulkan kerugian ekonomi, melumpuhkan aktifitas masyarakat, menimbulkan korban jiwa, masalah kesehatan, baik fisik maupun psikologis.

\section{METODE PELAKSANAAN}

Kegiatan asesmen psikologis korban bencana banjir di Aceh Tengah ini dilaksanakan pada hari Kamis tanggal 10 September 2020. Kegiatan ini dilaksanakan pada salah satu balai desa yang ada di Aceh Tengah.

Adapun tahapan Pelaksanaan kegiatan ini adalah sebagai berikut:

\section{A. Persiapan}

Dosen dan mahasiswa melakukan koordinasi dengan aparat desa untuk menyampaikan maksud dan tujuan dari kegiatan, mengkomunikasikan dengan aparat desa untuk menetapkan tempat yang akan digunakan untuk kegiatan asesmen psikologis, mempersiapkan intake interview untuk setiap korban. Absensi untuk korban juga disiapkan oleh tim dosen dan mahasiswa.

Absensi diberikan sebelum dimulai kegiatan asesmen, untuk itu korban mengisi absen kehadiran terlebih dahulu. Setelah absensi selesai, kegiatan selanjutnya pemaparan materi tentang dampak psikologis pada korban banjir bandang oleh tim dosen dalam kelompok kecil. Informasi ini diberikan agar para korban memahami tentang situasi psikologis yang terjadi setelah mengalami bencana.

B. Pelaksanaan

1. Asesmen

Pada tahap ini peserta dibagi menjadi 3 kelompok, tiap-tiap kelompok difasilitasi oleh satu dosen dan mahasiswa. Kemudian tim dosen melakukan intake interview pada seluruh anggota kelompok secara bergantian hingga selesai.

\section{Konseling Online}

Konseling online ini dilakukan setelah tim pelaksana melakukan asesmen awal dan mendapatkan hasil dari asesmen awal tersebut. Konseling online ini dilakukan untuk menunjang data yang telah didapatkan oleh tim pelaksana.

C. Tahap Evaluasi

\section{Sesi Review}

Pada tahap review ini, tim dosen menanyakan kembali kepada korban bencana tentang materi yang dipahami hari ini, kemudian menjelaskan pengalaman wawan cara yang dilakukan oleh tim dosen dalam 
bentuk diskusi dalam kelompok. Para korban juga diminta untuk memberikan kesan maupun pesan selama kegiatan dilakukan.

\section{Post Test}

Post test dilakukan setelah mendapatkan hasil dari asesmen dan konseling online. Post test ini diberikan kepada korban banjir bandang yang telah mendapatkan asesmen dan konseling online.

\section{HASIL DAN PEMBAHASAN}

Pengabdian masyarakat dosen psikologi bersama mahasiswa yang dilakukan di kota Takengon, Kota takengon berada terletak ditengahtengah kota. Akibat banjir bandang yang terjadi didaerah Kampung Paya Tumpi Baru Kecamatan Kebayakan Aceh Tengah mengakibatkan situasi dan kondisi daerah tersebut menjadi porak poranda.

Akibat banjir bandang yang terjadi rumah yang berada dekat lokasi kejadian banyak yang rusak, lokasi tersebut dipenuhi tanah disekitarnya, untuk sementara korban banjir bandang harus tinggal di pengungsian, pengungsian sementara tinggal di sekolah dan ada juga yang tinggal tidak jauh dari tempat kejadian.

Awal kejadian banyak LSM dan institusi baik lokal mau non lokal yang hadir dan memberikan bantuan kebutuhan pokok, dan pakaian guna memenuhi kebutuhan korban.

Kegiatan pegabdian ini dilakukan dalam tiga bentuk yaitu, pre test, assessment awal, follow up melalui konseling online, review hasil pertemuan 1 dan 2, post test. Dosen dan mahasiswa mengunjungi lokasi banjir bandang sehari setelah kejadian, kegiatan diawali dengan melakukan koordinasi dan komunikasi dengan dosen dan mahasiswa yang akan terlibat.

Kemudian dosen dan mahasiswa berangkat ke lokasi bencana bersamasama, setelah sampai di lokasi, tim dosen dan mahasiswa menyusun rencana kegiatan awal dengan membentuk tim untuk membagi 3 lokasi tempat pengungsian, sebelum masing-masing tim mendatangi korban, dosen dan mahasiswa mendiskusikan hal-hal yang akan ditanyakan kepada korban banjir bandang. Agar proses assessment lebih terstruktur.

Masing-masing tim bergerak mengunjungi tempat pengungsian, setelah sampai di tempat, tim memperkenalkan diri dan korban juga diminta untuk memperkenalkan diri, kemudian tim menjelaskan maksud dan tujuan kunjungan. Setelah sesi perkenalan selesai kegiatan dilanjutkan dengan memberikan pre test, pengungsi diberikan pre test yang berisi, pertanyaan yang berkaitan dengan stress, depresi dan traumatic.

Pre-test dilakukan agar tim memperoleh gambaran awal dari keadaan psikologis korban akibat banjir bandang. Pre-test dilakukan dengan cara bertanya kepada setiap korban. Setelah pre-test selesai, tim mulai bertanya tentang gambaran kejadian dan dampak fisik maupun psikologis korban setelah mengalami musibah banjir bandang. Korban banjir bandang yang ada terdiri dari bapak, ibu dan anak-anak mampu menjelaskan kejadian dengan baik. 
Kegiatan dilanjutkan dengan melakukan assesmen kepada para korban bencana yang ada di lokasi pengungsian. Para korban menjelaskan kronologis kejadian yang terjadi pada saat banjir ban dang terjadi, kejadian banjir bandang ini terjadi di hari rabu sekitar jam setengah tiga siang. Terdapat beberapa korban saat itu sedang tidak berada dirumah, mereka sedang di kebun ada juga yang sedang tidur di siang hari.

Sementara kondisi cuaca pada saat itu sudah sangat memprihatinkan, hujan deras, angin kencang, sehingga muncul kekhawatiran korban yang tinggal di rumah saat itu. Akhirnya mereka keluar rumah mencoba memperhatikan keadaan diluar rumah, karena takut longsor, salah satu korban mendatangi rumah korban suami istri yang lain, yang saat itu sedang bekerja di kebun, anak tinggal sendiri dirumah sendiri, saat itu sedang main sepeda.

Sebelum air datang kerumah korban, korban yang sedang bekerja di kebun sawit, merasakan perasaan yang tidak aman, takut akan terjadi sesuatu, ingat anak dirumah, sehingga perasaan panik, takut muncul dan buru-buru pulang ke rumah, dalam perjalanan kerumah perasaan takut itu tidak terkendali, sudah pasrah pada kejadian.

Salah satu korban lainnya sebelum air datang sempat menyelamatkan ijazah. Keadaan cuaca yang makin gemuruh, parabola sudah goyang-goyang diatas atap rumah. Lokasi rumah dibawah gunung tiba-tiba air datang dari atas dengan sangat cepat, sehingga korban juga tidak bisa mengambil barang-barang yang ada dirumah.
Para korban mengatakan hal yang terpikir saat itu hanya menyelamatkan diri, dan menyelamatkan anak yang orang tuanya sedang tidak berada dirumah karena bekerja di kebun. Saat air mengalir, korban banjir bandang hanya bisa melihat bagaimana air yang begitu deras menyapu bersih harta mereka, sampai ada seorang ibu harus mengikhlaskan mobil dan hondanya dibawa air pada saat itu, karena sudah tidak berdaya lagi, perasaan ihklas dan pasrah yang ada pada saat itu,

Berdasarkan hasil wawancara dan observasi yang dilakukan saat tahap asesmen didapatkan jugan gambaran psikologis para korban setelah mengalami kejadian banjir bandang. Gejala psikologis yang muncul sampai saat ini yaitu perasaan yang dialami seperti mimpi harus tinggal di pengungsian, harta benda habis, padahal hasil jerih payah selama ini dalam mencari nafkah.

Mereka bingung bagaimana hidup kedepannya merasa hidup dari nol lagi, sedih dengan keadaan mereka sekarang, ada perasaan takut untuk pulang kerumah, ada yang mengatakan tidak berani tinggal disitu lagi, masih terbayang bagaimana situasi banjir bandang itu terjadi, takut terjadi lagi, korban mengatakan kepada suami untuk mencari rumah sewa saja.

Perasaan pesimis terhadap masa depan. Sering sakit kepala bila ada pikiran, mudah marah, sedih dan gelisah, itu masih dirasakan sampai saat ini. Kurang semangat dalam menjalani aktivitas.

Setelah proses asesmen yang dilakukan, tim dosen dan mahasiswa 
memperoleh gambaran dan memahami kondi si korban banjir bandang, dalam proses ini juga tim memberikan psikoedukasi mengenai dampak kesehatan mental setelah mengalami pengalaman traumatis, informasi ini penting dilakukan karena keadaan psikologis korban yang masih belum stabil.

Tim memberikan gambaran kejadian yang telah mereka alami dan ceritakan sebelumnya, kemudian tim menjelaskan dampaknya sesuai dengan gejala yang muncul sekarang ini, untuk itu korban harus memiliki cara atau coping tepat untuk menghadapi dan menerima musibah ini.

Tim dosen dan mahasiswa mengkomunikasikan bahwa pertemuan pertama ini diharapkan dapat membantu korban banjir bandang untuk survive, untuk mengontrol perkembangan mental korban selanjutnya, tim akan melakukan follow up melalui konseling online.

Konseling online dilakukan pada tanggal 20 September 2020, tim dosen dan mahasiswa menghubungi beberapa korban banjir bandang yang memiliki gejala psikologis. Konseling online dilakukan dalam waktu satu jam setiap pertemuan. Hasil konseling online menggambarkan para korban bencana banjir bandang mulai bangkit, menata kembali kehidupannya, mulai kembali ke rumah masing-masing, mulai memperbaiki kondisi rumah dan bekerja seperti biasa.

Untuk mengukur keadaan psikologis para korban, tim dosen dan mahasiswa diberikan post test berupa skala ukur psikologis. Hasil post test menunjukkan bahwa korban banjir bandang memiliki perkembangan yang positif.

Masing masing tim bergerak
mengunjungi tempat pengungsian,
setelah sampai di tempat Tim memperkenalkan diri dan korban juga diminta untuk memperkenalkan diri, kemudian tim menjelaskan maksud dan tujuan kunjungan.

Setelah sesi perkenalan selesai kegiatan dilanjutkan dengan memberi kan pre test, pengungsi diberikan pre test yang berisi, pertanyaan yang berkaitan dengan stress, depresi dan traumatic. Pre-test dilakukan agar tim memperoleh gambaran awal dari keadaan psikologis korban akibat banjir bandang. Pre-test dilakukan dengan cara bertanya kepada setiap korban.

Setelah pre-test selesai, tim mulai bertanya tentang gambaran kejadian dan dampak fisik maupun psikologis korban setelah mengalami musibah banjir bandang. Korban banjir bandang yang ada terdiri dari bapak, ibu dan anakanak mampu menjelaskan kejadian dengan baik.

Manfaat kegiatan pengabdian ini sangat dirasakan oleh para pengungsi, mereka sangat berterima kasih dengan kedatangan dan kepedulian dari tim unimal. Dengan pertemuan hari ini korban memperoleh gambaran tentang kesehatan mental mereka, dan gejalagejala traumatis yang dirasakan mulai mempengaruhi aktivitas keseharian mereka.

Sehingga mereka dapat menemukan coping tepat, mendapat pemahaman dan keyakinan, cobaan ini semua datangnya dari Allah, Allah 
memberikan cobaan ini ada maksud dan tujuannya, bagaimana mereka terus dapat membangun sifat sabar, ihklas, optimis ke depannya akan lebih baik.

Setelah kegiatan pegabdian dilakukan, tim dosen berkoordinasi dengan media online unimal news untuk mempublikasi kegiatan pegabdian masyarakat oleh dosen dan mahasiswa psikologi unimal.

\section{SIMPULAN}

Bencana banjir bandang yang terjadi pada tanggal 13 Mei 2020 di Kampung Paya Tumpi Baru, dan bebe rapa kampung lainnya di Kabupaten Aceh Tengah, Propinsi Aceh, merupakan bencana banjir yang cukup besar dan memberikan dampak yang signifikan terhadap masyarakat. Fenomena kejadian banjir bandang ini telah mengugah tim psikologi untuk melaku kan kegiatan pengabdian kepada masya rakat korban bencana banjir bandang.

Kegiatan pengabdian dilakukan berjalan sesuai dengan tahapan pengabdian yang telah direncanakan mulai dari pre test, asesment awal, hingga post test.

Hasil dari kegiatan ini telah memberikan manfaat bagi korban banjir bandang salah satunya untuk pemulihan psikologis. Para korban merasa lebih tenang dan semangat menjalani kesehariannya setelah dilakukannya asesmen psikologis ini.

\section{DAFTAR PUSTAKA}

Bahagia, I. (2020, Mei 14). Banjir Bandang Terjadi di Sejumlah Wilayah Aceh Tengah, 57 Jiwa Mengungsi. Dipetik Juni 3. 2020, dari Kompas.com: https://regional.kompas.com/read/2020 /05/14/11594211/banjir-bandang-terjadidi-sejumlah-wilayah-aceh-tengah-57jiwa-mengungsi?page=all

Faturochman. (2020). Dampak Psikologis Bencana Alam. Yogyakarta: http://fatur.staff.ugm.ac.id/file/KORAN $\% 20-$ \%2oDampak\%2oPsikologis\%2oBencana \%2oAlam.pdf.

Larsen, M. C., Conde, M. T., \& Clark, R. A. (2001). Landslide Hazards Associated with Flash-Floods, with Examples from the Dexember, 1999 Disaster in Venezuela, Coping with Flash floods. Kluwer Academic Publisher , 259-275. 